I)E:PARTMENT OF THE INTERIOR

(I.S. GEOOL.OGICAL. SURVEY

\title{
GEOLOGIC MAP OF THE CROWNPOINT QUADRANGLE, MCKINLEY COUNTY, NEW MEXICO
}

By Jacques F. Robertson 
GEOLOGIC MAP SYMBOLS

COMMONLY USED ON MAPS OF THE UNITED STATES GEOLOGICAL SURVEY

(Special symbols are shown in explanation)

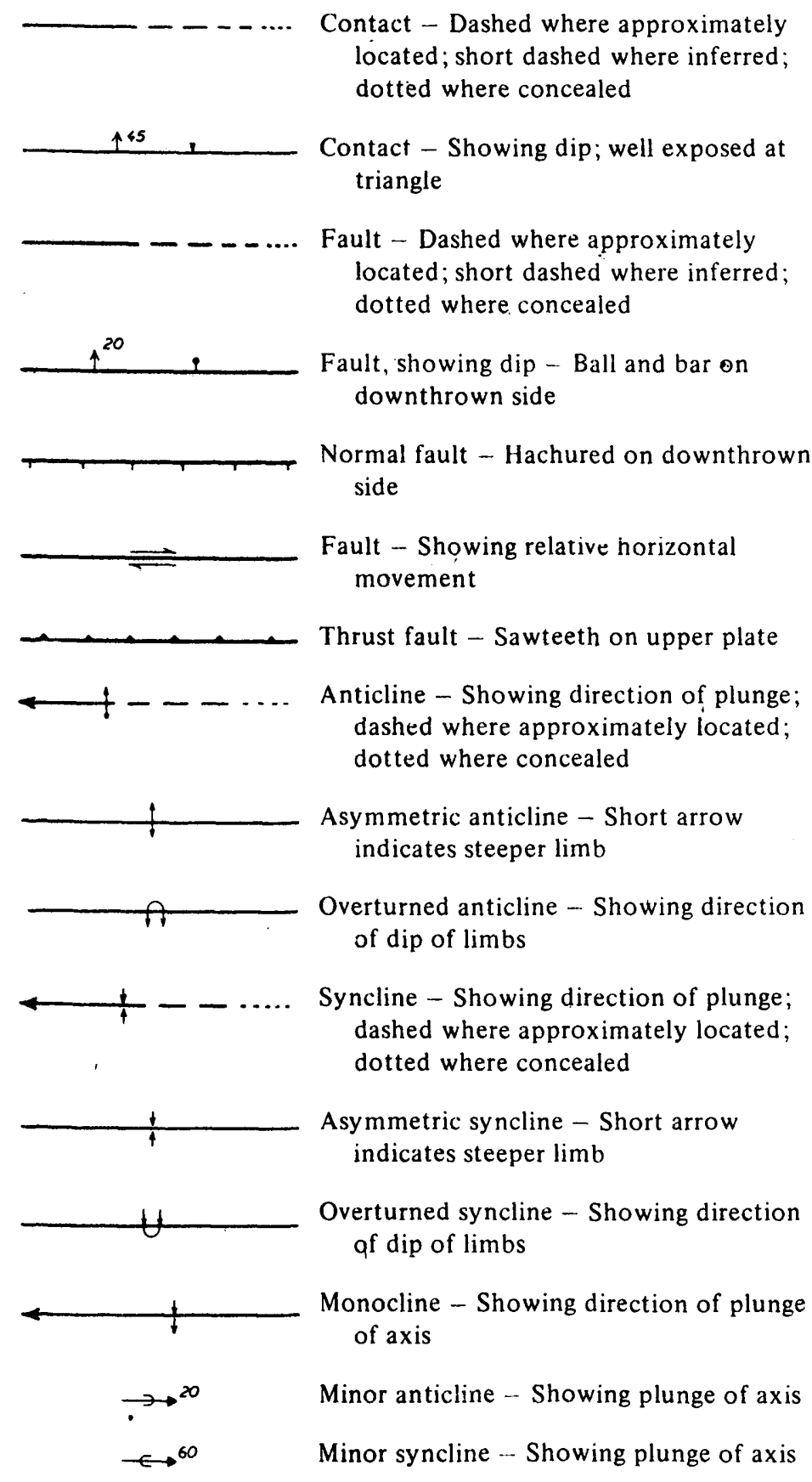

Strike and dip of beds - Ball indicates top of beds known from sedimentary structures

$\stackrel{70}{+}$ Inclined $\oplus$ Horizontal

+ Vertical $\stackrel{40}{4}$ Overturned

Strike and dip of foliation $\stackrel{20}{ }$ Inclined $\rightarrow$ Vertical $\downarrow$ Horizontal

Strike and dip of cleavage

$\stackrel{15}{ }$ Inclined Vertical it Horizontal

Bearing and plunge of lineation

$15 \leftarrow$ Inclined $\bullet$ Vertical $\longleftrightarrow$ Horizontal

Strike and dip of joints

$\ldots . .40$ Inclined $\rightarrow$ Vertical $\rightarrow$ Horizontal

Note: planar symbols (strike and dip of beds, foliation or schistosity, and cleavage) may be combined with linear symbols to record data observed at same locality by superimposed symbols at point of observation. Coexisting planar symbols are shown intersecting at point of observation.

Shafts

$\checkmark$ Vertical $\square$ Inclined

Adit, tunnel, or slope

$\succ$ Accessible $\nsim$ Inaccessible

$x$ Prospect

Quarry

Active Abandoned

Gravel pit

$\times$ Active $\nsucc$ abandoned

Oil well

- Drilling $\phi$ Shut-in $\phi$ Dry hole

* Gas Show of gas abandoned

- Oil Show of oil 